\title{
DIRETRIZES ESTRATÉGICAS VOLTADAS À ESTRUTURAÇÃO DE CONTEÚDO EM AMBIENTE ONLINE DE APRENDIZAGEM
}

\author{
CASCAVEL/PR FEVEREIRO/2018 \\ Maria Françoise da Silva Marques - Univel - francoisesmarques@gmail.com \\ Tipo: Investigação Científica (IC) \\ Natureza: Planejamento de Pesquisa \\ Categoria: Métodos e Tecnologias \\ Setor Educacional: EDUCAÇÃO MÉDIA E TECNOLÓGICA, EDUCAÇÃO SUPERIOR

\begin{abstract}
RESUMO
Este artigo trata de estratégias voltadas para implementação de práticas de ensino em plataformas de educação a distância unindo a tecnologia disponível e os métodos pedagógicos e cognitivos. Além disso, serão tratadas as teorias de aprendizagem como fundamentais quando da necessidade de escolha por determinada abordagem teórica devido às implicações sobre as formas de aprendizagem diante da utilização da tecnologia como apoio à educação. Os estilos de aprendizagem são brevemente analisados de forma que seja possível encontrar o melhor método de ensino e aprendizagem para ambientes virtuais de educação a distância com a utilização de metodologias ativas.
\end{abstract}

Palavras-chave: Ensino a distância, teorias de aprendizagem, estilos de aprendizagem, metodologias ativas.

\section{AGRADECIMENTOS}

AGRADEÇO A PROFESSORA TATIANA SANTOS DA MUST UNIVERSITY PELO INCENTIVO PARA A PUBLICAÇÃO DESTE ARTIGO. 
Diante de um mundo cada vez mais globalizado, a necessidade de adaptação constante que se faz presente em todas as áreas do conhecimento, é inevitável. A diversidade cultural é intrínseca a esse processo e influencia de maneira muito peculiar os processos de aprendizagem. Fatores como a competitividade acirrada no mercado de trabalho proporcionaram criar medidas alternativas para capacitação de indivíduos a fim de os tornarem aptos às suas funções. No intuito de atender à demanda crescente de pessoas em busca de qualificação profissional, mas que ao mesmo tempo tem disponibilidade limitada para estarem em bancos de escolas ou faculdades, surge a educação a distância como forma alternativa de atingir a esses objetivos. A partir desse momento, muito esforço tem sido aplicado ao desenvolvimento de métodos e plataformas educacionais que possibilitem o melhor e mais efetivo aprendizado. Contudo, o maior desafio é desmistificar a crença, por parte dos próprios educadores, de que somente o estudo tradicional é válido devido à interação física ocasionada por encontros de três a quatro horas diárias em uma sala de aula presencial.

Nesse ponto, um estudo aprofundado das teorias sociointeracionistas deve ser realizado, no intuito de buscar o entendimento de como as pessoas aprendem para, então, definir métodos de aprendizado que não sejam apenas reproduções de conteúdo, mas sim que proporcionem um aprendizado colaborativo que permita a absorção do que foi estudado de maneira que o aprendido se torne parte do indivíduo e que ele possa relacionar conceitos teóricos com práticas reais de vivência pessoal, não permitindo que a pessoa viva no abstrato sem entender o porquê estudou tal conceito ou ainda levá-la à frustação por não compreender a relação existente entre o estudo e a realidade. Por essa razão é tão importante que sejam analisados os métodos de aprendizagem e os meios de disponibilizar e proporcionar o aprendizado.

\section{As teorias sociointeracionistas e os aspectos socioculturais}

O aprendizado surtirá efeitos somente se conseguir atingir o indivíduo em seu âmago, para tanto, os aspectos culturais e sociais devem ser levados em consideração, por tratarem-se de elementos intrínsecos ao meio de vivência do indivíduo. É nesse ponto que estratégias destinadas ao desenvolvimento de e-learning devem ser pensadas no intuito de possibilitar o entendimento de todos em seus diferentes meios sociais, favorecendo um ambiente de aprendizado colaborativo.

"O homem normal não é social da mesma maneira aos seis meses ou aos vinte anos de idade, e, por conseguinte, sua individualidade não pode ser da mesma qualidade nesses dois diferentes níveis" (PIAGET, 1977, p. 242 apud LA TAILLE; OLIVEIRA; DANTAS, 1992, p. 12). Se um único homem é um ser diferente aos seis meses e depois 
aos vinte anos, chega-se a conclusão de que não há como ensinar todas as pessoas da mesma forma. Percebe-se, novamente, a necessidade de elaboração de estratégias e tomada de decisões adequadas a cada contexto de ensino e aprendizagem, inclusive no estabelecimento de etapas a serem utilizadas em ambientes virtuais de aprendizagem, de forma que o próprio aluno mediante a sua capacidade cognitiva possa, por ele mesmo, adquirir o conhecimento proposto sem a necessidade de intervenções constantes, mas tendo à sua disposição a parte mediadora que the propicie sanar dúvidas e complementar e explanar partes pouco entendíveis quando assim se fizer necessário. Em situações de ensino e aprendizagem não é aceitável que as informações sejam unilaterais, ou seja, a comunicação e a interação entre as partes é de total importância. Como partes dessa relação pode-se citar o professor, o aluno, os próprios colegas de estudo, a família, a sociedade entre outros.

\section{A sociedade do conhecimento na era tecnológica}

Tem-se apresentado como recorrente a questão de que os professores e instrutores precisam se adaptar às novas tecnologias. A conectividade na era da informação é cada vez mais abrangente, e na educação não seria diferente. Devido à Educação a Distância estar tomando proporções elevadas nos últimos anos, muitos especialistas da área têm se preocupado com questões referentes à estruturação de ambientes e-learning e metodologias de ensino e aprendizagem realmente eficazes.

Um dos pontos mais importantes a ser mencionado é a competência do docente em trabalhar com a educação a distância de forma dinâmica, acreditando que esta forma de aprendizagem é válida e merece todo o reconhecimento. Infelizmente, em muitas situações, ocorre de o docente não estar engajado nessa nova modalidade, o que acaba comprometendo todo o processo. Por outro lado, o aprendiz também precisa desenvolver algumas habilidades. É uma questão de trabalho em conjunto, ou seja, o professor deverá fazer a sua parte, sendo uma pessoa cativante em trabalhar os métodos de ensino e aprendizagem e o aluno deve estar comprometido com esse aprendizado.

A tecnologia funciona como ferramenta essencial nos processos de habilidade de comunicação, capacidade de aprender de forma independente, ética e responsabilidade, trabalho em equipe e flexibilidade, habilidade de pensamento, competências digitais, gestão do conhecimentoprincipalmente quando se fala em ensino a distância e, também, na aprendizagem híbrida que é o estudo que mescla as duas modalidades: ensino presencial e ensino online. Na relação de ensino, muitas variáveis não estáveis estão envolvidas, o que requer das partes, capacidades emocional e cognitiva aguçadas. A 
partir desse contexto, torna-se relevante um estudo mais aprofundado sobre as teorias da aprendizagem, no intuito de conhecer e entender os aspectos relacionados a como essas abordagens teóricas estão ligadas ao saber.

\section{Teorias, técnicas e estilos de aprendizagem}

De acordo com Moreira (1999) teorias de aprendizagem são utilizadas como um meio sistemático de análise voltado à área do conhecimento, que tentam explicar porque a aprendizagem funciona da forma como funciona. Entender sobre as teorias de aprendizagem se torna fundamental quando da necessidade de escolha por determinada abordagem teórica devido às implicações que esse fator pode provocar diante da utilização da tecnologia como apoio à educação. Algumas das principais teorias são citadas na sequência, conforme entendimento de Bates (2017).

Para a abordagem objetivista o material didático deve ser preciso e claro, sendo responsabilidade do aluno compreender e reproduzir mediante avaliações que exijam a resposta correta e a justificativa das mesmas. Nessa abordagem o professor está no controle e escolhe o que os alunos devem aprender, como devem adquirir o conhecimento e serem avaliados. A abordagem behaviorista investiga a influência do estímulo externo no comportamento humano, ou seja, o feedback é fator importante de reforço para a aprendizagem. Nessa abordagem as técnicas de memorização são comumente utilizadas, como forma melhor comunicação com crianças e adultos com capacidade cognitiva limitada, por exemplo.

Quanto à abordagem cognitivista, esta considera o ser humano como indivíduo com capacidade de tomar decisões e expressar ideias, além de possuir emoções. O foco dessa abordagem está concentrado na conciliação de novas informações com base em prévio conhecimento, buscando sentido nessa relação, identificando e descrevendo os processos mentais que afetam a aprendizagem. Diferentemente das abordagens behaviorista e cognitivista que enfocam o aprendizado embasado em regras e condições previsíveis e constantes, a abordagem construtivista se baseia na liberdade e na influência social, na qual o indivíduo constrói novos conhecimentos e não apenas os adquire por meio de memorização ou por transmissão. A abordagem conectivista tem grande importância para a sociedade digital, em sua aplicação as novas formas de conhecimento se dão pela construção coletiva, considerando que o conhecimento se dá além construção individual.

Todas as abordagens acima citadas possuem suas críticas devido aos seus aspectos peculiares, mas é visível que os métodos tradicionais de ensino tendem a perder espaço 
conforme a evolução tecnológica avança. Diante dessas abordagens, brevemente apresentadas, é possível perceber que cada uma delas possui suas vantagens e desvantagens, contudo, são igualmente importantes na construção do conhecimento e na estruturação de ambientes virtuais de aprendizagem.

As teorias socioconstrutivistas transmitem que a aprendizagem não acontece mais na mente do indivíduo em particular, mas torna-se presente em relações e interações, na qual o professor orienta os alunos nos processos de construção de conhecimento, deixando de limitar-se a transmitir informações. Já o conectivismo não considera o professor como único responsável por definir e organizar o conteúdo a ser estudado, logo considera o aluno como parte integrante e fundamental desse processo.

Em se tratando de educação e melhores práticas para a aprendizagem, não basta que sejam entendidas as teorias de aprendizagem apenas, mas que os estilos de aprendizagem sejam igualmente analisados com vistas a estabelecer o processo mais assertivamente. "Os estilos de aprendizagem afetam a forma de estar e de atuar dos sujeitos em diferentes planos da vida. Afetam, não só a forma como as pessoas aprendem, mas também como atuam em grupo, participam em atividades, se relacionam com os outros" (KOLB; SMITH,1996). Esse fator é um desafio para qualquer instituição e sua equipe multidisciplinar da área de educação a distância. Abaixo encontram-se alguns detalhamentos, de forma sucinta, sobre as formas de aprendizagem.

A forma visual utiliza estímulos visuais por meio de observações, gosto pela leitura e formação de imagens imaginárias a partir do abstrato, os indivíduos que a preferem costumam ter boa concentração e boa compreensão. A forma auditiva utiliza sons ou ruídos e palavras faladas para formar ideias e conceitos. Os indivíduos dessa forma de interpretação costumam aprender por meio de instruções verbais ou diálogos, geralmente não se atentam às imagens. Por último, a forma cinestésica utiliza a linguagem corporal como embasamento para interpretação de estímulos e, geralmente os indivíduos que a utilizam aprendem com a "mão na massa", não gostam muito de ler e sim de fazer.

Teóricos da área, entre eles Alonso, Gallego e Honey (2002) determinaram por meio de estudos que os estilos de aprendizagem estão embasados em traços cognitivos, afetivos e fisiológicos. Sendo assim, chegou-se ao estabelecimento dos seguintes estilos: estilo ativo, estilo reflexivo, estilo teórico e estilo pragmático.

O estilo ativo é marcado pela agilidade, pelo apreço a tarefas novas, valorizando a 
experiência. É composto por pessoas consideradas entusiastas, espontâneas, descobridoras e que gostam de se arriscarem. Pessoas que possuem o estilo reflexivo são aquelas que estudam, analisam e refletem, observando os acontecimentos por diversas perspectivas até chegarem a uma conclusão definitiva. Geralmente são pessoas ponderadas, conscientes, analíticas e receptivas. Quanto ao estilo teórico, este é voltado à lógica, teorias, princípios e modelos. Pessoas desse estilo buscam sintetizar estruturas de forma racional e objetiva voltadas ao perfeccionismo. Por fim, o estilo pragmático engloba pessoas que apreciam aplicar ideias na prática, fazer experimentos. As principais características dessas pessoas são a prática, o realismo, o produtivo.

\section{Métodos de aprendizagem com o uso de tecnologias}

O desafio atual na área de educação é encontrar o melhor método de ensino e aprendizagem para ambientes virtuais de educação a distância. Para tanto, embora haja muito acesso tecnológico disponível, a estratégia estrutural é ponto crucial para atingir com eficiência o objetivo almejado. Não obstante exista várias formas de disponibilizar conteúdo online, é imprescindível um estudo incansável de métodos, mídias e mecanismos a serem ofertados, sem desconsiderar as abordagens sobre teorias, técnicas e estilos de aprendizagem elaboradas por teóricos da área de educação.

Alguns métodos utilizados na educação presencial são muito utilizados na educação a distância, entre eles a aula expositiva que se utiliza de ferramentas próprias para resumir determinado conteúdo trabalhado pelos alunos, ou seja, [...] "o ponto importante da aula expositiva não é a transmissão de conteúdo (fatos, princípios, ideias), que o aluno pode obter pela simples leitura, mas a maneira como o especialista pensa sobre 0 assunto" (BATES, 2017, p. 119). As atividades de pesquisa também têm grande importância para a aprendizagem e, por isso, também se fazem presentes em ambientes online. A relevância se dá, principalmente, quando a pesquisa possui interação. Desse modo, ao combinar a teoria e a prática juntamente da interação entre alunos e professor, o resultado será um aprendizado mais abrangente. Há também a aprendizagem prática que Bates (2017) descreve como não apenas aprender a fazer algo, sendo uma atividade que leva o aluno a uma compreensão dos contextos apresentados para os quais o aprendizado será aplicado.

A formação que considera atividades práticas como parte de sua metodologia de ensino funciona muito bem quando é utilizada em ambientes híbridos. O ensino híbrido também chamado de blended learning se caracteriza por utilizar mais de uma forma de ensinar, mesclando o ensino convencional e o uso das tecnologias da informação tanto 
na sala de aula presencial quanto no ensino a distância. Essa metodologia facilita "[...] a personalização da aprendizagem - o que leva o estudante a aprender mais e melhor" (LOPES, 2015, p. 29). Nesse método de ensino não se exige do professor conhecimentos avançados em tecnologia, mas é necessário que ele consiga se adaptar a ela ao utilizar ferramentas importantes que proporcionem um eficaz aprendizado. A forma mais adequada é utilizar os conteúdos básicos como meio mais atrativo para os alunos, mediante objetivos de aprendizagem e avaliativos claros.

O design instrucional deve levar em consideração, ao estruturar um curso de educação a distância seja ele híbrido ou não, que cada "[...] aluno aprende no seu tempo e no seu modo de absorver a informação. Os que já assimilaram não precisam ficar esperando os que estão com dificuldade, podem avançar mais. E aprendem não só com o professor, mas por conta própria, uns com os outros" (LOPES, 2015, p. 31). Alguns métodos de ensino híbrido são mais comumente utilizados. LOPES (2015) apresenta alguns deles com base em pesquisas realizadas por pesquisadores do Instituto Clayton Christensen, que são: rotação; flex; à la carte e virtual enriquecido.

O método rotação reveza atividades conforme orientação do professor e de acordo com escala de horários. Pode ser feito em rotação por estações, na qual os alunos se reúnem em grupos para realizarem diversas atividades independentes, que ao mesmo tempo são integradas. O laboratório rotacional também pode ser aplicado, e consiste em realizar a rotação entre o laboratório e a sala de aula. Já a sala de aula invertida, também chamada de flipped classroom, se caracteriza pelo estudo teórico online e a prática aplicada presencialmente por meio de realização de atividades e outros. $\mathrm{E}$ a rotação individual que consiste em uma agenda particular do estudante usada para cumprir as atividades de que necessita.

O método flex contempla uma lista de atividades online a serem realizadas pelos alunos de acordo com seu ritmo. Nesse método, o professor fica à disposição do aluno para o esclarecimento de dúvidas. Por outro lado, no método à la carte, a organização das atividades é responsabilidade do aluno que deve defini-las junto com o educador. Nesse método a parte online pode ser realizada em qualquer local. Por fim, o método virtual enriquecido é aquele em que: "A experiência deve ser compartilhada por toda a escola e também consiste em um modelo disruptivo. Os estudantes alternam entre estudos presenciais e virtuais. O presencial pode ser apenas uma vez por semana, por exemplo" (LOPES, 2015, p. 33).

\section{Conclusão}


Conclui-se que a formação de uma educação eficaz tanto presencial quanto online é um conjunto de pensares e de fazeres que só funciona se ambas as partes, alunos e professores, estiverem dispostas a colaborarem para o alcance do objetivo final. A busca incansável pelo melhor ambiente virtual de aprendizagem com os melhores métodos e conteúdos abrangentes é um desafio para as instituições de ensino, seus educadores e toda a equipe multidisciplinar envolvida no processo de planejamento, estruturação, escolha e acompanhamento dos métodos escolhidos e utilizados para o objetivo fim que é o melhor aprendizado para os alunos.

A escolha das melhores práticas utilizadas no ambiente online são adquiridas mediante estudo aprofundado de variáveis ligadas à área pedagógica, considerando as melhores teorias e estilos de aprendizagem mais apropriados à realidade do que está sendo ofertado. Essa equipe multidisciplinar composta por designer instrucional, webdesigner,designer gráfico, equipe de vídeo, tutoria, professores e coordenadores é peça-chave na escolha dos melhores meios de alcançar o melhor método de ensino e aprendizagem. Trata-se de um conjunto de habilidades voltadas às mais adequadas práticas. Todos esses indivíduos possuem papéis claros e bem definidos, cada qual com sua responsabilidade.

O contexto sociocultural dos educandos, os estilos de aprendizagem juntamente das teorias elaboradas por especialistas da área de Pedagogia devem estar sempre em pauta quando o assunto é estabelecer metodologias ativas na educação. Muito embora algumas instituições já tenham alcançado êxito em suas abordagens de estudo a distância, o desafio não está terminado, pois em se tratando de tecnologias da informação, a mudança é constante e rápida, exigindo dos responsáveis pelo planejamento de ambientes de e-learning constantes atualizações e treinamentos com o intuito de manterem-se sempre a postos para as novas mudanças.

\section{Referências Bibliográficas}

ALONSO, C. M.; GALLEGO, D. J.; HONEY, P. Los estilos de aprendizaje: procedimientos de diagnósticoy mejora. Madrid: Mensajero, 2002.

BATES, T. Educar na era digital [livro eletrônico]: design, ensino e aprendizagem. 1 ed. São Paulo: Artesanato Educacional, 2017.

KOLB, D.A.; SMITH, S. User's guide for the learning-style inventory: a manual for 
teachers and trainers. Boston: TRGHayGroup, 1996.

LA TAILLE, Y; OLIVEIRA, M. K.; DANTAS, H. Piaget, Vygotsky, Wallon: teorias psicogenéticas em discussão. 15 ed. São Paulo: Summus, 1992.

LOPES, A. Ensino híbrido: tudo junto e misturado. Revista A Rede, ano 12, n. 103, dez. 2015. Disponível em: . Acesso em: 10 dez. 2017.

MOREIRA, M. A. Teorias de aprendizagem. São Paulo: EPU, 1999. 